\title{
The roles, responsibilities, and realities of married adolescent males and adolescent fathers: A brief literature review
}

Gary Barker

Jorge Lyra

Benedito Medrado

Follow this and additional works at: https://knowledgecommons.popcouncil.org/departments_sbsr-pgy

Part of the Family, Life Course, and Society Commons, and the International Public Health Commons How does access to this work benefit you? Let us know!

\section{Recommended Citation}

Barker, Gary, Jorge Lyra, and Benedito Medrado. 2004. "The roles, responsibilities, and realities of married adolescent males and adolescent fathers: A brief literature review," paper prepared for the WHO/UNFPA/ Population Council Technical Consultation on Married Adolescents. New York: Population Council. 


\title{
The Roles, Responsibilities, and Realities of Married Adolescent Males and Adolescent Fathers: A Brief Literature Review
}

\author{
Gary Barker, Instituto Promundo, Rio de Janeiro, Brazil \\ Jorge Lyra, Instituto Papai, Recife, Brazil \\ Benedito Medrado, Instituto Papai, Recife, Brazil
}

\section{Background paper prepared for the WHO/UNFPA/Population Council Technical Consultation on Married Adolescents, Geneva, 9-12 December 2003}

\footnotetext{
This paper draws extensively from several previous texts: (1) Barker, G. 2003. "Engaging adolescent boys and young men in promoting sexual and reproductive health: Lessons, research and programmatic challenges," in Adolescent and Youth Sexual and Reproductive Health: Charting Directions for a Second Generation of Programming, background document from a UNFPA workshop in collaboration with the Population Council, New York, 1-3 May 2002. New York: Population Council, pp 109-153; (2) Barker, G. (ed.). 2003. Men's Participation as Fathers in the Latin American and Caribbean Region: A Critical Literature Review with Policy Considerations, unpublished document prepared for the World Bank; (3) Barker, G. 2000. What About Boys? A Literature Review on the Health and Development of Adolescent Boys. Geneva: World Health Organization; and (4) Lyra, J. and B. Medrado. Marriage and Fatherhood in Male Adolescents: A Critical Literature Review, unpublished document prepared for the World Health Organization, 2003.
} 


\section{INTRODUCTION}

A useful starting point in discussing married adolescent males and adolescent fathers is to affirm that from the perspective of developing countries, we know relatively little about them. Furthermore, much of what we know is inferred from research with young women, or comes from a few specific regions in the world. Indeed, marriage and fatherhood among young men are generally poorly covered by the literature and by programs in the field of sexual and reproductive health. However, in recent years there has been a growing interest in the issue on the part of researchers, policymakers, and program staff. This interest has coincided with increasing attention in general to men, with gender studies, and with sexual and reproductive health initiatives.

We also start with the recognition that early marriage and early childbearing are much more prevalent among young women than young men, and that the potential and actual negative consequences of early marriage and childbearing are more significant among young women. Nonetheless, it is the behaviour and attitudes of men, within social contexts where gender hierarchies favour men over women, that often create young women's vulnerability. Thus even if early childbearing and marriage are less common among young men, the ways that boys and men are socialized and the ways they treat women are central to understanding and addressing the needs of young married women and adolescent mothers.

In developing regions of the world as a whole - and even more so in industrialized countries - early childbearing and early marriage among young men are relatively uncommon. Indeed, of 38 countries in which men were interviewed for the Demographic and Health Surveys, no respondents in the 30-34-year age group had a median age at marriage of less than 20 years. ${ }^{1}$ Table 1 indicates that in selected developing countries, between 2 percent and 14 percent of young men ages 15-19 have ever been married; this definition includes cohabitation and consensual unions. International data suggest that fatherhood among young men ages 15-19 is also relatively uncommon and is relatively low among young men ages 20-24 as well. Among 18 developing countries reviewed, a recent study carried out by the Alan Guttmacher Institute found that between 2 percent and 27 percent of young men ages 20-24 were already fathers. ${ }^{2}$

By comparison, in the same countries (see Table 1), between 5 percent and 51 percent of young women ages 15-19 have ever been married; indeed, in over half these countries more than 20 percent of 15-19-year-old girls are married. Furthermore, in contrast to the experiences of young women-who generally leave their homes of origin to live with their husbands' families and are more likely to do this while still adolescents - a large proportion of both unmarried and married young men continue to live with their natal families. In a literature review carried out by the Alan Guttmacher Institute (previously

\footnotetext{
${ }^{1}$ Haberland, Nicole, Erica Chong, and Hillary Bracken. 2003. "Married adolescents: An overview," background paper prepared for WHO/UNFPA/Population Council Technical Consultation on Married Adolescents, Geneva, 9-12 December.

${ }^{2}$ Alan Guttmacher Institute. 2003. In Their Own Right: Addressing the Sexual and Reproductive Health Needs of Men Worldwide. New York: Alan Guttmacher Institute.
} 
cited), among countries studied, about 50 percent to 80 percent of men ages 20-24 are still living with their parents. Most of these are unmarried young men, but even among the relatively small number of married young men, many often continue to live with their families.

In addition, we know that a substantial number of the partners of married adolescent girls and adolescent mothers are older men (and thus are not adolescents themselves). In many settings, girls are married at a young age to men who may be many years older than they are (35 percent of the husbands of married girls ages 15-19 in developing countries, excluding China, are ten or more years older than their wives ${ }^{3}$ ), and often do not choose their husbands. For example, in a study in Egypt, among females who married before the age of 16-about 40 percent of currently married females - only one in ten chose her husband. Nonetheless, data also suggest that a sizable proportion of the partners of adolescent mothers and married adolescent women are also adolescents, or at least young adults, although usually slightly older.

Behind these trends are several fundamental social expectations. One is the nearly universal social expectation that men are to be the main financial providers for their families. In concrete terms, this means that in some settings men are often not able to marry - that is, they are not seen as marriageable or attractive to potential partners and their families - until they have some kind of employment and income. The other chief social expectation in many developing regions is that the sexual activity of girls and women is to be confined to marriage. These two social expectations, with local variation, produce a situation in which men require more years to obtain employment, while girls are seen as marriageable at earlier ages than men. Hence, in some settings it is often older men - whether older by three to four years or ten or more years - who have the financial resources, or their family's support, to marry and begin childbearing.

To be sure, as we review these general trends in patterns of marriage and childbearing among adolescents and young adults, it is important to recognize variation across regions, in rural versus urban contexts, within countries, and by social class. One of the key differences across regions is the nature of early sexual activity, that is, whether it happens within the context of marriage or before marriage. The proportion of unmarried sexually active adolescent girls is higher in Latin America and the Caribbean than in other regions, particularly in Asia, with mixed patterns in sub-Saharan Africa. In addition, in Latin America and the Caribbean (and some parts of sub-Saharan Africa), many couples live together or form an informal union prior to formalizing a union. ${ }^{4}$ Overall, however, the majority of sexually active adolescent girls in developing countries are married; therefore, data on sexually active (more often unmarried) adolescent girls in Latin America, the Caribbean, and parts of sub-Saharan Africa do not necessarily reflect the experience of the majority of (more often married) adolescent girls in some other

\footnotetext{
${ }^{3}$ United Nations Department of Economic and Social Affairs. 2000. World Marriage Patterns 2000. New York: United Nations.

${ }^{4}$ Barker, G. (ed.). 2003. Men's Participation as Fathers in the Latin American and Caribbean Region: A Critical Literature Review with Policy Considerations, unpublished document prepared for the World Bank.
} 
developing regions. By the same token, recommendations and policy proposals related to controlling some kinds of early marriage, while important in many parts of Africa and Asia, are of less relevance for the realities of Latin America, for example.

As we review the literature in the next section, it is important to acknowledge that much of the research and literature on adolescent fathers comes from Latin America, the Caribbean, North America, and Europe. This may be because in these settings-where adolescent childbearing and adolescent marriages are less prevalent than in much of Asia and Africa-such behaviour is seen as "out of order" or problematic and thus interesting to study.

In what follows, this paper reviews some of the literature on young married men and young fathers, concluding with specific suggestions for engaging young men to promote better reproductive and sexual health and more favourable life outcomes for married adolescent women and for young men.

\section{SALIENT ISSUES FOR UNDERSTANDING YOUNG FATHERS AND YOUNG MARRIED ADOLESCENT MALES}

In this section, we discuss some of the relevant issues related to young fathers and young married adolescent males that emerge in the literature, including the supposed freedom of young men to choose partners; sexuality and reproductive health; the relationship between educational attainment, work, and family formation for young men; genderbased violence among young couples; and HIV/AIDS prevention concerns. The subsequent section will discuss some of the specific research on adolescent fathers.

\section{The Supposed Freedom of Young Men to Choose Partners}

To what extent is early marriage for adolescent males a matter of free choice? Much of the discussion about early marriage for young women has focused on coercion or arranged or forced unions. While research on young men's experiences of partner selection is limited, particularly within settings where arranged marriages are common, some authors question the assumption that adolescent boys and young men have freedom in their selection of spouses or in the timing of marriage. Researchers working in India suggest that while boys and men are undoubtedly privileged, their two most significant life decisions - their choice of occupation and of their mate - are largely made by adults in the family rather than themselves. ${ }^{5}$ Qualitative research with young men in a variety of settings suggests that young and adult men experience significant pressure from family in terms of their choice of mate and the timing of their marriages.

This pressure, of course, has different ramifications, and men in nearly all settings have a greater ability to operate in the public realms of schooling and the workplace, which provides them with some "room to maneuver" when subjected to family pressure.

\footnotetext{
${ }^{5}$ Schweder, R. 2002. Why Men Barbecue: Essays on Cultural Anthropology. Cambridge, MA: Harvard University Press.
} 
Nonetheless, it is pertinent to ask how much choice young men experience in choosing their partners.

A useful illustration of this is found in interviews with Christian and Muslim university students ages 24-31 recently carried out in Kaduna, Nigeria. ${ }^{6}$ All of the young men interviewed complained of the difficulties of completing their studies and acquiring employment. They were subject to conflicting pressures; on the one hand, they were expected to finish university to support their families (most were expected to become the main providers for their extended families). At the same time, nearly all of the young men reported some pressure from their families to marry; similarly, all reported that they were delaying marriage so they could complete their education and improve their work prospects (the men would be considered by local standards to be lower-middle class).

Salim: Some families want to know if you are a man. They want to know if you are man enough to handle a woman, in bed, I mean. And so they will say, "You have all these beautiful women around you, why don't you think about getting married. Can't you handle them?"

Abdul: Yeah, if you are not talking about women [with your family], they may think you are impotent or something. . . . You have to have a strategy [to convince your family that you are interested in women].

Some of the young men added:

Ayo: In some parts of the southwest of Nigeria [where he is from], you [as a man] have to prove your fertility before you get married. You have to get a girl pregnant before you are married to prove that you are a man.

Ali: You know the truth is, we get married to have children. . . You prove yourself to your family by how many children you have. You know, your mother will say that she wants to have grandchildren.

The discourse among both Christian and Muslim young men was that marriage and childbearing were as much about satisfying others - particularly their families — as they were about satisfying their own desires for family formation. These quotations are illustrative of the family pressures that some young men face in terms of the timing and selection of mates. For young men and women, family formation and, in particular, the timing of family formation are frequently tied to family expectations and sometimes pressure and coercion.

\section{Young Men, Sexuality, and Reproductive Health}

As can be seen by the limited examples above, much of the behaviour of young men is about "performing" expected roles of manhood-showing sexual prowess or ability,

\footnotetext{
${ }^{6}$ Ongoing research project for the Africa Division, World Bank, on young men, socialization, and HIV/AIDS in sub-Saharan Africa, G. Barker and C. Ricardo, Instituto Promundo.
} 
proving fertility, and achieving the socially expected role of husband and provider. This is an important point for adolescent reproductive and sexual health programs to consider when taking into account the social context of sexual activity, marriage, and fertility, for both girls and boys.

In most developing countries boys' sexual initiation usually takes place outside of marriage, while girls' first sexual experiences usually take place within marriage. ${ }^{7} \mathrm{We}$ also know that sexual initiation is involuntary for too many girls. What do we know about boys' early sexual experiences? Studies from around the world find that young males often view sexual initiation as a way to prove that they are "real men" and to gain status in their male peer groups. For example, in a study in Argentina 45 percent of boys in secondary school cited "sexual desire and physical necessity" as their motivation for having sex, whereas 68 percent of girls in the same setting cited the desire for a more intimate relationship as their motivation. ${ }^{8}$ Boys often proudly share their heterosexual "conquests" with others in their male peer groups, while sexual self-doubts or lack of sexual experience is kept hidden. In a study in Guinea, boys said they worried that if they did not have sex with a girl, their reputation would suffer among their male peers. ${ }^{9}$

In various studies, boys report that they constantly have to prove their manhood through sexual activity or else risk having their manhood or virility questioned. ${ }^{10}$ Thus, while it is true that boys' first sexual encounters are more likely than girls' to be self-willed, social pressure frequently is involved. Some young men report being taken to sex workers by male family members and describe this pressured initiation as a source of stress. The pressure on boys is, of course, far different from the overt coercion and sexual abuse and violence that young women often report in many parts of the world. Nonetheless, the social pressure that many boys experience begs the question of whether boys engage in early sexual activity for their own desire or to fulfill a social role.

Another supposition about boys and sexuality is that they have more information on such issues than do girls. However, various studies confirm that boys often pretend that they know a lot about sex, while they are frequently uninformed or misinformed. ${ }^{11}$ Adolescent boys worldwide largely rely on the media and on their self-taught peers for information about sex.

\footnotetext{
${ }^{7}$ Singh, Susheela, Deirdre Wulf, Renee Samara, and Yvette P. Cuca. 2000. "Gender differences in the timing of first intercourse: Data from 14 countries," International Family Planning Perspectives 26(1): 2128,43 .

${ }^{8}$ Necchi, S. and M. Schufer. 1998. Adolescente Varón: Iniciación Sexual y Conducta Reproductiva [The adolescent male: Sexual initiation and reproductive behaviour]. Buenos Aires: Programa de Adolescencia, Hospital de Clínicas, Universidad de Buenos Aires/OMS (WHO)/CONICET.

${ }^{9}$ Gorgen, R., M. Yansane, M. Marx, and D. Millimounou. 1998. "Sexual behaviors and attitudes among unmarried youths in Guinea," International Family Planning Perspectives 24(2): 65-71.

${ }^{10}$ Barker, G. 2000. What About Boys? A Literature Review on the Health and Development of Adolescent Boys. Geneva: World Health Organization.

${ }^{11}$ Barker, G. 2003. "Engaging adolescent boys and young men in promoting sexual and reproductive health: Lessons, research and programmatic challenges," in Adolescent and Youth Sexual and Reproductive Health: Charting Directions for a Second Generation of Programming, background document from a UNPFA workshop in collaboration with the Population Council, New York, 1-3 May 2002. New York: Population Council, pp. 109-153.
} 
Frequently programs and research in the area of sexual and reproductive health have focused on the negative aspects of young men's attitudes and behaviours toward women. Adolescent males and adult men are often viewed as oversexed and promiscuous. Too often young men are seen either as enslaved to hormonal rages or as sexual predators who prey on younger women and girls. In some discussions about men in Africa- the epicenter of the HIV/AIDS epidemic - the discourse is often even more inflammatory. ${ }^{12}$ For example, in Uganda a national law against "defilement" makes it a criminal offence, punishable by imprisonment, for a young man to have sexual relations with a young woman under the age of 18 . In discussions with young men and staff at youth-serving organizations (including juvenile incarceration centers) recently carried out by Barker and Ricardo, young men reported that the law frequently stigmatizes them as sexual predators, and the discourse of staff who work with youth suggested this as well.

To be sure, exploitative and coerced sex is too frequent, and older men-who tend to have more income than younger men-are a source of HIV infection and other sexual health risks for many young women in Africa and elsewhere. Too many womenparticularly in countries such as Botswana and South Africa - are the victims of sexual violence, which in addition to being a tremendous human rights violation, contributes to the spread of HIV. Such accounts of violence against women do not, however, tell the whole story of heterosexual young men and their relationships with women.

For example, in a review of data on men's sexual behaviour worldwide, researchers at the Panos Institute in the United Kingdom estimated that 25 percent of men worldwide carry out some sexual behaviour that puts themselves and their partners at risk for HIV/AIDS. ${ }^{13}$ While this number is significant, it means that many, perhaps most, of the world's men generally practice safer sex. While the sexual violence and unsafe sexual behaviour of a sizable minority of the world's men cannot be glossed over, it is useful to keep this point of reference in mind.

Finally, young men, with the exception of those in parts of Africa and the Caribbean, generally have penetrative sex earlier and with more partners before forming stable relationships than do young women. Young men are also more likely than young women to have occasional sexual partners outside of a stable relationship. The fact that many young men, married and unmarried, have multiple sexual partners has important reproductive and sexual health implications for young men and women, notably regarding transmission of sexually transmitted infections (STIs), including HIV. This is a key rationale for seeking to understand and respond to the sexual and reproductive needs and realities of young men.

\footnotetext{
${ }^{12}$ Barker, G. 2005. Dying to Be Men: Youth, Masculinity and Social Exclusion. London: Routledge; and ongoing research project for the Africa Division, World Bank, on young men, socialization, and HIV/AIDS in sub-Saharan Africa, G. Barker and C. Ricardo, Instituto Promundo.

${ }^{13}$ Panos Institute. 1998. "AIDS and men: Old problem, new angle," Panos HIV/AIDS Briefing no. 6.

London: Panos Institute.
} 


\section{Relationship Between Educational Attainment, Work, and Family Formation}

Educational attainment is thought to be a major factor influencing age at marriage and at childbearing for both boys and girls. ${ }^{14}$ In most of sub-Saharan Africa and Asia, boys' enrolment rates are higher than girls', although these rates have been equalizing in recent years. Girls' enrolment in primary education in developing countries increased from 93 percent in 1990 to 96 percent in 1999. According to figures from the UN Educational, Scientific and Cultural Organization (UNESCO) for 2002, 86 countries have already achieved gender parity in primary education, and 35 are close to doing so. ${ }^{15}$ In parts of Latin America and the Caribbean and in a few countries in Asia, girls are enrolled at slightly higher rates than boys. ${ }^{16}$

Links between work and reproduction generally are different for boys and girls. This fact bears on boys' and girls' differential socialization and identity formation, as well as on their sexual and reproductive behaviour. Enrolment in school, engagement in meaningful work, and access to savings or some form of financial independence have been linked to and promoted as ways for young females to postpone childbearing and gain greater control over reproductive decisionmaking. There is some evidence that higher levels of educational attainment are associated with lower rates of early childbearing among young males as well as females. ${ }^{17}$

For most young males, work is the chief basis of their identity, or the main cultural and personal requisite for achieving "manhood." For a young man, being able to financially support himself and his family is generally a precursor to reproduction, as seen earlier in the examples of the young men from Nigeria. Thus, achieving the provider role (i.e., acquiring gainful employment) may be a signal event for many young males to begin childbearing. For other males, having an unplanned child may be an impetus to acquire employment. For the most part, however, there is limited research on the links between young males' education, employment, and childbearing, suggesting the need for additional research and programmatic attention to this topic.

Some research suggests that girls' roles may be expanding in some parts of the world, while boys' roles are remaining largely the same. ${ }^{18}$ In many places nearly 20 years of advocacy and at least some policy change related to women's and girls' rights have served to expand many young females' options and roles. But young males' opportunities

\footnotetext{
${ }^{14}$ Notably, some of the decline in early marriage is explained by the increase in schooling for women. Mensch, Barbara, Susheela Singh, and John Casterline. 2004. "Trends in the timing of first marriage among men and women in the developing world," presentation at the annual meeting of the Population Association of America, Boston, 1-3 April.

${ }^{15}$ UNESCO. 2002. Education for All Global Monitoring Report: Is the World on Track? Montreal: UNESCO Institute for Statistics.

${ }^{16}$ Barker, G. 2000. What About Boys? A Literature Review on the Health and Development of Adolescent Boys. Geneva: World Health Organization; and Pan American Health Organization, World Health Organization and Population Reference Bureau. 2003. Gender, Health, and Development in the Americas: 2003. Washington, DC.

${ }^{17}$ What About Boys? (see previous note).

${ }^{18}$ Ibid.
} 
to discuss - and modify - their identities and roles continue to be limited. If gender roles are changing in some parts of the world, achieving work and income continues to be the chief social role ascribed to men. As a Chilean working-class man told one researcher: "Yo era lo que era mi trabajo" [I was what my work was]. ${ }^{19}$ Similarly, a low-income young man interviewed in Rio de Janeiro said, "Work isn't everything, but it's almost everything." ${ }^{, 20}$ Another low-income young man interviewed in Brazil said this:

Interviewer: . . . what does it mean [for a man] to work?

Murilo: You have to work. Because you want to have your [own] things and at least when you're 20 or 25 , you want your things organized . . . together [have a family and support yourself]. And if you don't work, you're gonna have to rob to make a living. You're not going to be [as a man] walking around with nothing to do or wear. I prefer to work [than to steal]. ${ }^{21}$

The social meaning of work for boys and young men must be taken into account when examining youth unemployment figures. Data from the International Labour Organization suggest that as many as 70 million young people ages 15-24 are currently unemployed, and that in the next ten years 500 million young people will enter the world's work force. ${ }^{22}$ While rates vary by country, urban/rural setting, and educational attainment, among other variables, limited data suggest that youth unemployment rates are two to three times higher than those for adult unemployment. Limited data from subSaharan Africa suggest that nearly one-quarter of young people ages 15-24 are economically active, the majority of them young men. ${ }^{23}$ Similarly, in many countries of the Asia-Pacific region youth unemployment accounts for over 30 percent of total unemployment. ${ }^{24}$ In Latin America and the Caribbean, young people account for more than 50 percent of the unemployed. Data from several countries in the region indicate youth unemployment rates ranging from 30 percent to 37 percent. $^{25}$

Various qualitative and ethnographic studies on male identity have affirmed that for young (and adult) men, not having work and the income and status associated with it is to lack status before one's family and potential and actual female partners. ${ }^{26}$ For lowincome young men who often lack other means of affirming their identity, being without

\footnotetext{
${ }^{19}$ Cited in Barker, G. (ed.). 2003. "Men's participation as fathers in the Latin American and Caribbean region: A critical literature review with policy considerations," unpublished document prepared for the World Bank.

${ }^{20}$ Barker, G. 2001. "Peace boys in a war zone: Identity and coping among adolescent men in a favela in Rio de Janeiro, Brazil," doctoral dissertation, Loyola University-Chicago, Erikson Institute.

${ }^{21}$ Ibid.

${ }^{22}$ Okojie, C. (2003). "Employment creation for youth in Africa: The gender dimension," paper presented at Jobs for Youth: National Strategies for Employment Promotion, 15-16 June, Geneva, Switzerland.

${ }^{23}$ Ibid.

${ }^{24}$ Ghee, L.T. 2002. "Youth and employment in the Asia-Pacific region: Prospects and challenges," paper presented at the Youth Employment Summit, Alexandria, Egypt, 7-11 September.

${ }^{25}$ Hopenhayn, M. 2002. "Youth and employment in Latin America and the Caribbean: Problems, prospects, and options," paper presented at the Youth Employment Summit, Alexandria, Egypt, 7-11 September.

${ }^{26}$ Barker, G. 2005. Dying to Be Men: Youth, Masculinity and Social Exclusion. London: Routledge.
} 
work and income is not merely a question of poverty, unemployment, or underemployment, but is an affront to their very sense of self; work is how they define who they are in their social settings. Young women in these same settings may find meaningful, albeit limited, social roles and a sense of self as mothers or partners of men, but young men rarely find a socially recognized identity in carrying out domestic chores or caring for children.

Furthermore, numerous studies confirm links between having access to meaningful employment and lack of involvement in violence and delinquency. ${ }^{27}$ Employment patterns also influence behaviours related to HIV/AIDS. Several studies have examined the sexual behaviour of young and adult men who must migrate for work or are distant from their families and/or regular partners. Studies on HIV-related behaviors among young men in the military and men who have to migrate for work have confirmed specific sexual risk behaviours that often occur in such settings. ${ }^{28}$

\section{Gender-Based Violence Among Young Couples}

Most of the research on gender-based violence has focused on adults or older couples, but a sizable body of research is beginning to offer insights on violence among younger couples, including those who are married and those who are dating. For example, studies of university and secondary school students in the United States and New Zealand find that between 20 percent and 50 percent of males and females say they have experienced physical aggression during a dating relationship (although young men's physical violence toward women is nearly always more severe). In survey research carried out by Instituto Promundo and Instituto Noos in low-income areas in Rio de Janeiro, some two-thirds of young men believed that violence against women was acceptable when a woman is unfaithful, and 25 percent of men ages 15-65 had used physical violence at least once against an intimate female partner. Young men ages 20-24 had higher rates of selfreported physical violence against women in their current or most recent intimate relationship than any other age group. ${ }^{29}$ Thirty-two percent of the young men reported that they had ever been physically violent with their current or most recent primary partner.

In the qualitative portion of the study, young men frequently said that in dating/courtship relationships, "things" were less serious, and conflicts would rarely lead a young man to use physical violence. However, once the couple was cohabiting, which tended to occur between the ages of 20 and 24 years, the relationships were reported to be stressful and fraught with conflict. Many young men, as a result, reported that they used physical violence against their partners. This violence emerged, they said, when the woman did

\footnotetext{
${ }^{27}$ See for example, Sampson, R.J. and J.H. Laub. 1993. Crime in the Making: Pathways and Turning Points through Life. Cambridge, MA: Harvard University Press; and Wilson, W. J. 1996. When Work Disappears: The World of the New Urban Poor. New York: Vintage Books.

${ }^{28}$ See for example, Campbell, C. 2001. “'Going underground and going after women': Masculinity and HIV transmission amongst black workers on the gold mines," in Morrell, R. (ed.), Changing Men in Southern Africa. New York: Zed Books, pp. 275-286.

${ }^{29}$ Instituto Promundo and Instituto Noos. 2003. "Men, gender-based violence and sexual and reproductive health: A study with men in Rio de Janeiro, Brazil.” Rio de Janeiro: Instituto Promundo and Instituto Noos.
} 
not "fulfill her part of the bargain." This might include not taking care of children, not taking care of the house, spending too much time with her friends, or being suspected of sexual infidelity.

Older men suggested that over time they learned how to cohabit with women in less physically violent ways. It is clear from numerous studies that older women report higher lifetime rates of victimization through physical violence by a male partner than do younger women. ${ }^{30}$ However, it may be that early in relationships among adolescents and young adults, young men's use of violence is more commonplace than among older couples. ${ }^{31}$ It is possible that time spent together, along with maturation of the individuals, may contribute to less physically violent cohabitation for some couples. These brief examples suggest the need for additional research on young men's use of domestic violence and their perceptions of their early relationships.

\section{Implications for HIV/AIDS}

As previously stated, limited data suggest that even after marriage, whether as adolescents or adults, young men are more likely than young women to have outside sexual partners. Because young married women may not feel they are in a position to discuss or otherwise negotiate sex with their partners, the sexual behaviour of many younger or older married men may put men and their female partners at risk of acquiring HIV/AIDS. For example, in a study in Rwanda, 20 percent of HIV-positive women interviewed had only one partner; 45 percent contracted the virus from their husbands. And a 1995 study in 18 countries found that more men than women reported having occasional or outside partners. ${ }^{32}$ Men also generally have more sexual partners over their lifetimes and prior to marriage. In Costa Rica, 70 percent of women compared to only 9 percent of men had only one sexual partner. In the United Kingdom, 24 percent of men compared to only 7 percent of women reported ten or more sexual partners over their lifetimes. ${ }^{33}$

Numerous studies have found that young and adult men are more likely to use condoms with occasional partners than with stable partners; however, inconsistent use with occasional partners - and the proportion of men who have occasional partners - implies a high risk of HIV and other STIs. In a study in Zimbabwe, men interviewed had sex with sex workers an average of seven times per month, but used condoms in only about half of those encounters. ${ }^{34}$ Even in settings such as Brazil, where condom use among young men is high, it is still inconsistent. In a study of 224 young men ages 15-24, 53 percent reported using a condom during last sex with a primary partner, and 76 percent reported condom use with an occasional partner. Twenty-two percent of the men reported being

\footnotetext{
${ }^{30}$ Heise, L. (1994) "Gender-based abuse: The global epidemic," Caderno de Saúde Pública, 10/1: 135-145.

${ }^{31}$ Instituto Promundo and Instituto Noos. 2003. "Men, gender-based violence and sexual and reproductive health: A study with men in Rio de Janeiro, Brazil." Rio de Janeiro: Instituto Promundo and Instituto Noos.

${ }^{32}$ Cited in Panos Institute. 1998. "AIDS and men: Old problem, new angle," Panos HIV/AIDS Briefing no.

6, December 1998. London: Panos Institute.

${ }^{33}$ Ibid.

${ }^{34}$ Ibid.
} 
married or living with a partner; condom use was consistently higher with occasional partners than with stable partners, married or otherwise. ${ }^{35}$

In India, Nepal, parts of southern Africa, and Central America, many young men (and young husbands) migrate for work and often have sexual encounters with sex workers. Anecdotal accounts suggest that the pressure to migrate for work comes shortly after marriage, when many young men are expected to contribute to their natal families and/or contribute to their newly constituted families. Returning home, many of these young men may expose their younger female partners to HIV and STIs. In this way, young women and men are made vulnerable to HIV/AIDS by rigid social expectations of what it means to be a man, notably the pressure to provide financially for one's family at any cost and the freedom and pressure to have additional sexual partners outside of a stable union.

The challenges to promoting mutual monogamy and condom use among men are numerous and rooted in men's attitudes about sex and have been widely described in other documents. Many men believe that only penetrative sex "counts" and that other forms of sexual expression are "adolescent" or unsatisfying. For some men, having unsafe sex may be appealing precisely because it is risky and spontaneous. These are just a few of the examples of the challenges of engaging young men-including young married men-in HIV/AIDS prevention.

Finally, program experiences in diverse settings have indicated that young men can and do change their attitudes and behaviours when engaged in group and community interventions that take into account their needs and perspectives and that promote more gender-equitable ways of being men.

Program $\mathrm{H}$, an international alliance working with young men to promote gender equality, has carried out evaluation research confirming the efficacy of its efforts to change social norms and the specific behaviours of young men. The initiative, led by Instituto Promundo and including other NGO partners, includes (1) group educational activities to promote attitude changes among young men, both in terms of sexual and reproductive health, and in their overall attitudes toward young women; (2) lifestyle social marketing campaigns to promote more equitable attitudes on the part of young men; (3) campaigns to engage young men more effectively in public health services, including reproductive and sexual health services; and (4) an evaluation model, called the GEM Scale - Gender Equitable Men Scale_-developed specifically for working with young men (in collaboration with the Horizons Program/Population Council). Results from an evaluation of Program $\mathrm{H}$ activities in Brazil found that after participating in program activities, stable partners increased their use of condoms by more than 25 percent, and young men's attitudes related to gender changed in positive ways on 18 of 24 indicators used. In addition, self-reported symptoms of sexually transmitted infections (STIs) decreased by more than 45 percent in one of the two communities involved. ${ }^{36}$

\footnotetext{
${ }^{35}$ Unpublished results from a study on male gender norms and HIV being carried out by the Horizons Program and Instituto Promundo, J. Pulerwitz and G. Barker, principal investigators.

${ }^{36}$ Horizons, 2004. "Promoting healthy relationships and HIV/STI prevention for young men: Positive findings from an intervention study in Brazil," Research Update. Washington, DC: Population Council.
} 


\section{ADOLESCENT FATHERHOOD}

As stated previously, the experiences and roles of adolescent fathers, married or unmarried, have been noticeably missing from research and programmatic agendas related to adolescents' sexual and reproductive health. While various surveys have asked young men whether they have ever gotten a partner pregnant, research is lacking on young males' attitudes toward fatherhood, their experiences and needs as fathers, and their involvement and their desire for involvement as fathers.

Limited research suggests that in some regions adolescent fathers, like adolescent mothers (married or unmarried), may face social pressure to drop out of school to support their children and are less likely to complete secondary school than their nonparent peers. ${ }^{37}$ Research suggests that many unmarried young males may initially deny responsibility and paternity when faced with a possible pregnancy, in large part because of the financial burden associated with caring for a child. For example, research in Mexico suggests that an adolescent father's employment and financial situation were important factors in determining how they reacted to pregnancy and fatherhood. ${ }^{38}$ In most of the world, deep-rooted gender stereotypes hold that the main role of a father, whether adolescent or adult, is that of financial provider. Only recently have a handful of programs begun to examine the multiple roles of fathers and promote greater involvement by fathers in child care and maternal health.

Unmarried adolescent fathers frequently face entrenched stereotypes perpetuated by their parents, the parents of the child's mother, the mother herself, and service providers. There are widespread beliefs that an adolescent father who does not marry the mother of his child is being irresponsible, when in fact his motivations often may be complex. In some cases, young fathers may want to be involved with the child, but the child's mother will not allow that involvement. Young fathers who are unemployed may feel constrained in their parenting role because they do not believe they have the right to interact with the child if they are not financially providing for him or her. Such nuances have not been well studied and are often neglected in discussions about adolescent fathers. ${ }^{39}$

Studies in the United States suggest that, contrary to stereotypes, many adolescent fathers try to support their children and the mothers of their children. Such assistance, however, often is informal, because most adolescent fathers in low-income settings are generally unemployed and possess limited education. Accordingly, they often make other arrangements to support the child, which may include providing child care or involving

\footnotetext{
${ }^{37}$ Barker, G. 2000. What About Boys? A Literature Review on the Health and Development of Adolescent Boys. Geneva: World Health Organization.

${ }^{38}$ Atkin, L. and J. Alatorre. 1991. "The psychological meaning of pregnancy among adolescents in México city," paper presented at the Biennial Meeting of the Society for Research in Child Development. Seattle, 18-20 April.

${ }^{39}$ Lyra, J. 1998. "Paternidade adolescente: Da investigacao a intervencao" [Adolescent fatherhood: From research to intervention], in M. Arilha, S. Ridenti, and B. Medrado (eds.), Homens e masculinidades: Outras palavras. São Paulo: ECOS and Editora 34.
} 
their family of origin in providing care. Some studies have also found that establishing paternity recognition is key and is often a precursor to the involvement of unmarried adolescent fathers in the lives of their children. ${ }^{40}$

Data from another US study suggest that on many measures adolescent fathers differ little from adult fathers. A sample of men who had fathered children as adolescents and others who had done so as adults found that men who were fathers as adolescents experienced levels of marital satisfaction and instability in relationships similar to those of older men. Interestingly, however, men who became fathers in adolescence reported a greater increase in parental satisfaction in the course of their relationships than men who became fathers after the age of $20 .^{41}$

Research in the Caribbean has explored these issues in depth, describing patterns of father involvement from adolescence through adulthood. Qualitative data on household formation in the Caribbean indicate a common pattern among the majority of lowerincome families in which young, unmarried mothers and their children live with their extended family or enlist other members of the extended family to care for children, while young, unmarried fathers maintain a visiting, nonresident relationship with their children that may or may not imply migration for work. A young father may in some cases spend a larger portion of his resources on his own needs and with his male peers. Many young men in Jamaica and elsewhere in the Caribbean father children while they are adolescents as a way of establishing their manhood even before they have the means to support children. Later in life, these same men may form more permanent unions and devote considerable resources to "inside children"- those with whom they currently reside. These men may or may not have maintained contact with their earlier offspring. While the literature has often described such family formation in dysfunctional terms, some researchers argue that such behaviour is a functional and historically based pattern to ensure family survival in the face of postslavery poverty and lingering social exclusion. ${ }^{42}$

Programs that support young fathers must begin by grappling with cultural beliefs that inhibit men's involvement with children and by moving males beyond the notion that the only test of a good father is whether he can financially support his child/children. A handful of programs that work with young fathers - mostly in Latin America, the Caribbean, North America, and Western Europe-hypothesize that young men's lack of knowledge about fathering or how to care for young children is one of the greatest impediments to promoting wider involvement by fathers. While young mothers are similarly often unprepared for parenthood, societies generally foster child care skills in girls and encourage females of all ages to care for children. Boys and men generally lack the equivalent societal support and context for learning child care skills - although a few

\footnotetext{
${ }^{40}$ Adams, G., K. Pittman, and R. O’Brien. 1993. "Adolescent and young adult fathers: Problems and solutions," in A. Lawson and D. Rhode, The Politics of Pregnancy: Adolescent Sexuality and Public Policy. New Haven: Yale University Press, pp. 216-237.

${ }^{41}$ Heath, T. and P. McKenry. 1993. "Adult family life of men who fathered as adolescents," Families in Society (special issue: Fathers) 74(91): 36-45.

${ }^{42}$ Brown, J. and B. Chevannes. 1998. "Why Man Stay So": An Examination of Gender Socialization in the Caribbean. Kingston, Jamaica: University of the West Indies.
} 
programs in developing countries are beginning to address these issues. Indeed, a small but growing number of programs - mostly in Australia, parts of Latin America and the Caribbean, and North America-have suggested a positive impact on adolescent fathers, their partners, and their children. Such programs have also come to see the need to develop comprehensive and multifaceted strategies that engage not only the father, but also the mother and her family, the father's family of origin, and diverse professionals in social services, education, and health.

Some examples of such programs include the Conscious Fathering Project in the U.S. (Seattle), which works with fathers during their partner's pregnancy and for the first few months after childbirth, or Fathers Plus in the UK, which provides courses to social service agencies to make their services and practices more accessible to fathers. ${ }^{43}$

These brief examples suggest the complexity of understanding unmarried adolescent fathers and the need to avoid simplistic assumptions about so-called absent unmarried adolescent fathers. Another challenge when calling attention to married or unmarried young fathers is the lingering question about the roles of fathers. In recent years, there has been significant research (mostly in Western Europe, North America, and the Caribbean) in the child development and public health field about whether fathers matter, a question that extends to adolescent fathers or fathers/partners of adolescent mothers. Taken as a whole, the emerging consensus in the fields of child development and health is that men's participation as fathers, as co-parents, and as partners with women in domestic chores and childcare and childrearing does matter. ${ }^{44}$ Depending on the quality of the father's presence, child development can be enhanced. Father presence is generally also positive for household income. When fathers participate in household chores, in general women benefit. And finally, positive engagement as caregivers and fathers is generally good for men themselves.

\section{FINAL CONSIDERATIONS}

With this brief overview, we offer the following recommendations for research, program development, and policy when considering the roles of young fathers:

- Rather than a stand-alone area within the area of adolescent mothers and married adolescent women, we recommend that issues of young married men and adolescent fathers be incorporated within all aspects of research, program development, and policy regarding married adolescents and adolescent parents.

- We suggest that existing documents and UN pronouncements on the importance of engaging men and boys in the promotion of gender equality be taken into account when making recommendations on the issue of married adolescents. These include

\footnotetext{
${ }^{43}$ See Bartlett, D. and N. Vann. 2004 "Review of the state of practical work," in Supporting Fathers: Contributions from the International Fatherhood Summit 2003. Early Childhood Development: Practice and Reflections. No. 20, Bernard Van Leer Foundation (The Hague), pp. 78-107.

${ }^{44}$ Barker, G. (ed.). 2003. Men's Participation as Fathers in the Latin American and Caribbean Region: A Critical Literature Review with Policy Considerations, unpublished document prepared for the World Bank. See also C. Lewis. and M. Lamb. "Fathers: The research perspective," in Supporting Fathers (see previous note), pp 44-77.
} 
previous documents by UNAIDS on men and AIDS; the Cairo Programme of Action; WHO documents on adolescent boys; and the recommendations from the Commission on the Status of Women, made at their expert meeting on the role of men and boys in achieving gender equality (Brasilia, 2003).

Research recommendations:

- Listen to the needs of the partners of adolescent mothers and married adolescent women and seek to understand the cultural context of gender and manhood as related to the demand for young brides and the pressure that may exist for men to marry young women.

- Conduct additional research on the sexual initiation of young men and the preference for "virgins" or sexually inexperienced girls/young women.

- Carry out research on the social norms related to gender and manhood that encourage and reinforce age differences between partners.

- Conduct research with "positive deviants" (a.k.a. positive outliers or voices of resistance) - men who do not support early marriage. Such research is extremely useful for designing interventions and campaigns by identifying "cracks" in existing social norms. Indeed, a more complete picture will be obtained by looking at attitudes across the continuum of how young men act in their relationships with their partners and their children.

- Carry out research on younger adolescent boys to understand the early socialization patterns that promote early marriage.

- Support research on family formation, pressures to work, migration patterns, and sexual behaviour among young married men and young fathers who migrate for work.

- Include additional questions both for and on men and male partners within existing research instruments (e.g., Demographic and Health Surveys), particularly questions more appropriate to understanding the realities of young men, and obtain information from them directly rather than indirectly.

Program recommendations:

- Carry out campaigns targeting social norms and take advantage of positive outliers who already question early marriage and the age difference between married partners. These campaigns could be associated with existing campaigns targeting men, such as the White Ribbon Campaign (the campaign of men working to end violence against women), and could include men who serve as role models for young men and demonstrate positive aspects of manhood.

- Provide training for service providers in the health and education sectors on the aforementioned issues, including offering skills in how to engage young people in discussions about these issues.

- Implement workplace-based approaches in the formal and informal sector, as well as via the military (i.e., places where large numbers of men can easily be reached).

- Engage young fathers and young husbands/partners in activities conducive to maternal health. A number of programs in India and sub-Saharan Africa are beginning to engage men (many of them younger) in maternal health programs, some 
with positive evaluated outcomes. ${ }^{45}$ These program examples could be considered as models for expansion. Some of these programs also involve men in the prevention of mother-to-child transmission of HIV.

- Engage young fathers and young husbands/partners in sexual and reproductive health programs. Many programs in sub-Saharan Africa and Asia have taken this approach, with generally positive results. In Zimbabwe, for example, a joint project of the Centre for Population Studies at the University of Zimbabwe and the Horizons Program engaged couples via antenatal clinics to promote maternal and child health and reduce mother-to-child transmission of HIV.$^{46}$ Whether and to what degree these programs serve married adolescents and what special attention this population needs are areas for intervention research.

- Work with young men to help them consider their potential future roles as fathers or as caregivers in general. The majority of the world's adult men will at some point in their lives be fathers, although this is a role for which men often are unprepared. A few programs that work with young men are doing this. In Trinidad and Tobago, the nongovernmental organization (NGO) Servol requires that all participants in its vocational training - both young men and women - spend some time in daycare centres caring for young children. For young men, Servol staff report that this often is their first experience in caring for young children or providing caregiving of any kind. In Brazil and Mexico a coalition of four NGOs (Promundo, Papai, Salud y Genero, and Ecos) has developed a field-tested curriculum with group educational activities for young men designed to promote changes in attitudes related to gender, including a set of activities on fatherhood and caregiving. As mentioned above, this series of manuals - entitled Program H-also includes an impact evaluation study to measure quantitatively changes in attitudes and behaviours on the part of young men, including attitudes related to fatherhood.

- Support young men who already are fathers by providing information, counselling, and training on the fatherhood role. Instituto Papai in Brazil is one of a handful of NGOs in sub-Saharan Africa and Latin America and the Caribbean carrying out these kinds of activities.

- Enhance vocational training/employment creation to take into account the issue of early marriage and early parenthood. This may include the need to consider special programs for young people in areas with high rates of migration for work.

- Reflect carefully on when to work with couples together, and when to work with men and women separately.

Policy and advocacy recommendations:

- Carry out awareness-raising workshops/events for senior policymakers.

- Include the issue of early marriage within existing HIV/AIDS policy.

- Prepare briefing documents for policymakers that present existing and evaluated models for engaging young men, including interventions that have been shown to lead to attitude and behaviour change among men. In short, this would entail

\footnotetext{
${ }^{45}$ Reaching Men to Improve Reproductive Health for All: An Implementation Guide. Washington, DC: Population Reference Bureau (InterAgency Gender Working Group), 2003.

${ }^{46}$ Horizons, 2001. "Studies in brief," Horizons Report.
} 
demonstrating to policymakers that it is possible and desirable to change some aspects of traditional male roles.

- Influence existing HIV/AIDS funding, particularly in sub-Saharan Africa, making changing norms about masculinity part of national AIDS campaigns.

- Carry out efforts to show that engaging men is part of promoting gender equality and that funding such efforts does not detract from funding for efforts to enhance the status of women.

Finally, a major aspect of existing gender inequity is the great disparity between fathers and mothers regarding roles and responsibilities related to childrearing. Data suggest that, worldwide, fathers contribute far less time to the direct care of children than do mothers, although there is tremendous variation across countries and among men. Studies from diverse settings find that fathers contribute about one-third to one-fourth of the time that mothers do to direct child care. However, even if they are not as involved in caring for children, fathers make decisions about the use of household income for children's wellbeing, education, and health care, in addition to contributing income. Engaging fathersand young men who will likely be fathers in the future - has the potential to set the stage for greater gender equality over the life course. 
Table 1. Percentage of men and women aged 15-19 and 20-24 who have ever been married

\begin{tabular}{|l|c|c|c|c|}
\hline Region and country & \multicolumn{2}{|c|}{$\mathbf{1 5}-\mathbf{1 9}$ years old } & \multicolumn{2}{c|}{$\mathbf{2 0 - 2 4}$ years old } \\
\hline Sub-Saharan Africa & Men & Women & Men & Women \\
\hline Burkina Faso & 3 & 35 & 17 & 86 \\
\hline Ethiopia & 6 & 31 & 31 & 71 \\
\hline Nigeria & 7 & 36 & 23 & 70 \\
\hline Uganda & 11 & 50 & 55 & 88 \\
\hline Zimbabwe & 2 & 21 & 27 & 72 \\
\hline Asia & & & & \\
\hline Bangladesh & 5 & 51 & 32 & 90 \\
\hline China & 2 & 5 & 38 & 59 \\
\hline India & 10 & 36 & 40 & 83 \\
\hline Nepal & 14 & 42 & 62 & 86 \\
\hline Philippines & 3 & 11 & 27 & 44 \\
\hline Middle East and North Africa & & & & \\
\hline Egypt & 3 & 16 & 12 & 56 \\
\hline Morocco & n.a. & 11 & n.a. & 40 \\
\hline Turkey & 4 & 16 & 28 & 62 \\
\hline Latin America and the Caribbean & & & & \\
\hline Brazil & 3 & 17 & 31 & 53 \\
\hline Dominican Republic & 4 & 22 & 30 & 55 \\
\hline Mexico & 6 & 16 & 39 & 55 \\
\hline Nicaragua & n.a. & 37 & n.a. & 78 \\
\hline Peru & 4 & 13 & 33 & 52 \\
\hline Industrialized countries & & & & \\
\hline Great Britain & 1 & 2 & 12 & 25 \\
\hline Italy & 1 & 3 & 6 & 23 \\
\hline Japan & 0 & 1 & 6 & 14 \\
\hline Sweden & 1 & 4 & 19 & 33 \\
\hline United States & 0 & 0 & 2 & 7 \\
\hline Note: Mara & & & \\
\hline
\end{tabular}

Note: Marriage includes cohabitation and consensual unions.

Source: United Nations Department of Economic and Social Affairs. 2000. World Marriage Patterns 2000. New York: United Nations. 